\title{
Paideusis
}

\section{Sensitive Controversy in Teaching to Be Critical}

\section{Michelle Forrest}

Volume 18, Number 1, 2009

URI: https://id.erudit.org/iderudit/1072341ar

DOI: https://doi.org/10.7202/1072341ar

See table of contents

Publisher(s)

Canadian Philosophy of Education Society

ISSN

0838-4517 (print)

1916-0348 (digital)

Explore this journal

Cite this article

Forrest, M. (2009). Sensitive Controversy in Teaching to Be Critical. Paideusis, 18(1), 80-93. https://doi.org/10.7202/1072341ar

\section{Article abstract}

The sensitive nature of certain controversies is particularly problematic for teaching across difference. Questions as to what makes a controversy sensitive and how care and empathy are implicated in discussing it are considered through examples connected to the author's own practice and in light of the traditional rationalist concept of critical spirit and feminist strong reflexivity. The suggestion is made that discussing sensitive controversy requires a 'doubled view' and that this is needed at all levels of inquiry.
This document is protected by copyright law. Use of the services of Erudit (including reproduction) is subject to its terms and conditions, which can be viewed online.

https://apropos.erudit.org/en/users/policy-on-use/ 


\title{
Sensitive Controversy in Teaching to Be Critical
}

\author{
MICHELLE FORREST \\ Mount Saint Vincent University
}

\begin{abstract}
The sensitive nature of certain controversies is particularly problematic for teaching across difference. Questions as to what makes a controversy sensitive and how care and empatby are implicated in discussing it are considered through examples connected to the author's own practice and in light of the traditional rationalist concept of critical spirit and feminist strong reflexivity. The suggestion is made that discussing sensitive controversy requires a 'doubled view' and that this is needed at all levels of inquiry.
\end{abstract}

\section{Introduction}

One of the difficult balances to achieve in teaching philosophy of education to pre-service teachers is that of discussing a controversial issue the substance of which has had a direct negative impact upon one or more students in the class. The problem concerning sensitive controversies in the classroom is one I first encountered when, as a novice teacher, I taught The Merchant of Venice in high school language arts. Shylock, the Jewish money-lender, is the villain of the piece and Shakespeare evokes all the stereotypes of his day to heap invective upon him. Though I did not and still do not believe the play should be avoided in secondary language arts, I did feel uncomfortable even as I taught the context of anti-Semitism from which Shakespeare's characterization sprang. I had a pervasive sense of empathy for any Jewish student in the class and couldn't help but wonder how he or she might be feeling. And yet, the history of anti-Semitism, racism, sexism and other systemic bigotry needs to be examined, especially by those most at risk of adopting the quick and easy stereotypes that propel intolerant attitudes.

Different controversies are sensitive to greater or lesser degrees depending upon numerous variables such as the current climate of public debate around a given controversy and the way in which it comes to light. As William Hare (1985) points out, "[i]t is important to notice that value questions can reach the public forum... in a different way. This difference hinges upon the way in which we are disturbed" (112). Take, for example, the claim of Digby, Nova Scotia residents that the local RCMP detachment is guilty of racist behaviour and attitudes. Following an incident involving an off-duty Mountie and a member of Digby's African Nova Scotian community, black citizens affirmed that RCMP harassment and intimidation had been long-standing, while Mounties blamed a previous detachment commander, a few specific officers, and exaggerated reports by the media (Medel 2008a \& b). What if, while the community is in the midst of heated debate over this incident, a teacher in the predominantly white local high school decides to raise the news incident in her class for debate? How might we consider this decision? On the one hand, while community feelings remain raw, this could be a risky or even irresponsible move on the part of the teacher. The way in which the community has been disturbed by the issue of racism is such that a class discussion could generate more heat than light and even escalate tempers in the wider community. Though a teacher may be keen to teach students to be critical in light of community issues pertinent to their immediate experience, there are safety and

(C) Copyright 2009. The author, Michelle Forrest, assigns to Paideusis the right of first publication and educational and non-profit institutions a non-exclusive license to use this document for personal use and in courses of instruction provided that the article is used in full and this copyright statement is reproduced. Any other usage is probibited without the express permission of the author. 
other considerations that impinge upon this educational aim. On the other hand, what would this fictitious Digby teacher be implying by not taking up this troubling incident involving racism and the questions it raises? In addition to the inevitable focus on the incident within the community where it occurred, there was ongoing, province-wide attention by news media, unlikely to have escaped students' notice. To remain silent within the school could be an equally risky strategy since tension and fear fester and ripen when mistaken assumptions and half-baked ideas are left unaired. To say nothing could imply a range of untenable notions, not least of which are that sensitive issues do not belong in the school curriculum, high-school students are too immature to discuss with seriousness matters of grave concern to adults, and racism is not an important problem in this community. The ways in which this incident disturbed small-town Nova Scotia, the province with the largest percentage of African Canadian citizens, can hardly be hived off from the formal school curriculum without raising charges of systemic racism, which lie at the heart of the incident itself.

Hare (1985) reminds us that since education is an interdisciplinary affair, there are times when philosophical analysis is not sufficient to provide the necessary evidence for determining whether one should include within one's curriculum a specific controversy at a specific time. Hare provides a thorough and convincing logical argument for the place of controversy in the curriculum, but adds that a practical recommendation regarding the inclusion of a particular issue in its context requires further evidence such as psychological evidence that a certain group could not understand the controversy, or sociological evidence that any presentation of the issue would lead to a "distorted grasp" (115). While the community of Digby struggles with the situation and race relations are particularly strained, it is possible that an in-class discussion on racism could lead to a distorted grasp. A teacher faced with such a situation and believing that this is the moment to raise the issue precisely because it is hotly debated in the community, may reason that, as it is her responsibility not to shirk from controversy, this is her best chance to engage students in one. Hare's point is instructive here since she must weigh her belief in the importance of including controversy against other educationally relevant considerations. Though controversy has a vital role to play in the formal curriculum, not to take up a sensitive issue under circumstances of imminent volatility could demonstrate the wiser judgment. Certainly the teacher would be wise not to wade in without serious reflection on the range of possible responses from students, how she might react appropriately and have the necessary resources to do so, and the potential consequences of her decision and reactions upon the wider community in light of students' best interests.

When faced with a sensitive controversy, how is the teacher to weigh her pedagogical choices along a continuum between taking up the issue at the risk of exacerbating a volatile situation, and avoiding it thereby reneging on her responsibility to teach students to be critical? Is there guidance to be found within the conceptualization of critical thinking as an educational ideal? These questions shall be taken up as follows: I will examine what makes a controversy sensitive and how caring and empathy are involved in its treatment, and then move to that component of the concept of critical thinking referred to as the critical spirit, suggesting how the teacher might respond in discussions of sensitive controversy such that she acts in the spirit of criticism. I will then look at strong reflexivity in terms of its importance to the critical spirit and conclude with some thoughts on working across social difference as taking a 'doubled view,' as suggested by Todd (2003).

\section{Sensitive Controversy, Empathy and Caring}

What is at issue, then, is a subset of controversies, here referred to as 'sensitive,' the very discussion of which can exacerbate the hurt and indignity already experienced by discussion participants as a result of the realities the controversy represents. George Dei (1996) points out that, in respect to the concepts of

race and racism, "educators cannot overlook the fact that the theoretical exercise of debating the intellectual validity of these concepts can be painful for individuals who live the experiences being 
conceptualized" (28). To focus then on the teacher education classroom, here are two questions, variations on which frequently emerge in my philosophy of education course as we discuss case studies from schooling: ${ }^{1}$

1) In the interests of promoting anti-racism education, should we drop from the curriculum even those books in which racist language and behaviour are depicted as deplorable?

2) In light of the statistics on teen pregnancy among young adolescents, should the facts about abortion be included in the middle-school health education curriculum?

An important part of teacher education involves the realization that because of her or his influential position as authority figure, the teacher must consider when, how, or if it is appropriate to express a personal view on a topic under discussion. As the example of race relations in the town of Digby suggests, these considerations are of particular importance in discussing controversies of a sensitive nature.

Before examining what it is that makes a controversy 'sensitive,' let us consider what makes a disagreement controversial. Though there can be various reasons for and conditions under which people disagree, Dearden (1984) reserves the term 'controversy' for a disagreement on which "contrary views can be held ... without those views being contrary to reason" (86). As McLaughlin (2003) points out, it is Dearden's isolation of this epistemic criterion of controversy that helps us identify which type of disagreement is appropriate for attention in the classroom (150). ${ }^{2}$ Part of Dearden's purpose in providing an epistemic criterion of the controversial is to further refine a mere behavioural criterion, which, by naming as 'controversial' any disagreement by numbers of people, fails to distinguish disputes over matters trivial from those of a deeper kind. If teachers are to include controversy in their curricula, Dearden's distinction is useful in making judicious choices. Although it is never possible to predict or control fully when a controversial matter might arise in classroom discussion, the teacher can design lessons so as to raise issues strategically, thereby attempting to develop students' logical and analytical skills in discussions of simple matters of disagreement before moving to full-blown controversies. It may be prudent to begin with those controversies already resolved by theoretical developments (e.g., Ptolemaic vs. Copernican systems, divine right of kings vs. democratic theory). This allows for skill development without the complications that unresolved controversy might entail, while demonstrating to students how what is controversial at one point in time can change with empirical and theoretical developments. The teacher could then introduce discussion of topical controversies (e.g., competing definitions of 'black hole,' direct vs. representative democracy), and these may usefully precede those of a sensitive nature such as the questions above regarding race and abortion. ${ }^{3}$ What is it, then, that further distinguishes a controversy as one of a sensitive kind?

In fact, it is not the controversy that is sensitive, but rather the person responding to it who is very open to or acutely affected by the matter under discussion. The phrase "a sensitive controversy" is a transferred epithet. In the noun plus modifying clause "a controversy to which people are sensitive" the epithet after the noun is condensed into the word 'sensitive,' which is then transferred to the adjective position. More correctly, then, to examine what makes a controversy 'sensitive' is to consider why people are sensitive to certain topics. Certainly there are countless reasons why an individual might be acutely affected by the discussion of a controversy; however, for our purposes, we shall set aside reasons of accidental association (e.g., the topic reminds one of something upsetting but not

${ }^{1}$ The book of case studies I use is What To Do? Case Studies for Educators by Hare and Portelli, 2003.

2 McLaughlin does not adhere to Dearden's strict use of the term 'controversy'; rather, he uses the term more broadly as is the case in everyday speech and he distinguishes 'grounded' controversies as the deeper disagreements about matters epistemological or ethical.

3 The foregoing account of the introduction of discussion issues along a continuum from simple disagreement to sensitive controversy could apply to the planning of instruction for schools as well as for teacher education. 
substantively related to the matter at hand), and those of personal affect incidental to the controversy in question (e.g., an individual is upset by the emotional impact of people disagreeing). Although it is possible and even probable that both of the foregoing reasons may also impinge upon the person sensitive to a controversy in the sense I shall next distinguish, I am suggesting these reasons for sensitivity be set aside when they exist devoid of the special distinction deemed 'sensitive controversy.' The reason for sensitivity which I suggest be used to distinguish that which we deem a 'sensitive controversy' is the following: a person is acutely affected as a result of having been directly involved and/or having experienced the reality to which the controversy substantively refers. For example, question 1 raises a sensitive controversy in my philosophy of education class because in the predominantly white culture of Canadian universities any student of colour will have been subject to the racism under discussion. Question 2 is sensitive because in a Canadian teacher education class students are predominantly female. Odds are more than one of the women in the class will have had an abortion, have had to contemplate having an abortion, or acted in a support role for a friend or relative facing such a decision. ${ }^{4}$

The dilemma for the teacher is this. At one extreme, in discussing a sensitive controversy the very discussion of it by anyone unsympathetic to those sensitive to it can inflict upon them further pain and indignity, as the quote from Dei (1996) above indicates. On the other hand, fear of offending those sensitive to the realities of the controversy can manifest itself in the silence of political correctness, thereby stifling honest dialogue and leaving prospective teachers unprepared for critical discussion of controversy in their own classrooms. In my experience in the teacher education classroom, the newcomer to a discussion of a given sensitive issue is, in most instances, not intending to be hurtful with his or her comments; but what is hypothetical for one person can be a bitter reality for another. A common tack of the teacher is to attempt to develop empathy in those who, by virtue of not being directly implicated in the realities of the issue under discussion, are unable to understand how views offered on it, as if from a distance, can be hurtful to those sensitive to it. The very tone of voice used to stand back and generalize can evoke painful memories of rationalizations used to justify past injustices.

Typically, the pedagogical project of developing empathy in one's students has taken the form of appealing to their imaginations by describing how life might be for a victim of the circumstances entailed in an issue under discussion. It has been one of the roles of literature to re-create the imaginary world with which the reader may engage. Storytelling and drawing from historical evidence serve to help students understand what it might be like to be in the place of the other. If, for example, I imagine myself a person of colour in a white society, constantly bound by assumptions and points of view not my own, I can imagine being infuriated listening to members of the dominant race debate the pros and cons of censoring all depictions of racism from the classroom. If I put myself in the place of the woman who has had an abortion or had to contemplate having one, I can imagine how difficult it would be to listen to others, particularly men, cavalierly offer definitive views on the subject. Being able to put oneself in the position of someone gravely affected by the issue suggests that one possesses what Passmore (1985) terms "sympathetic imagination": "a capacity to understand how other people are feeling. Such imagination" says Passmore, "is inherent in the capacity to cooperate. Always difficult, it becomes even more difficult when the people in question are culturally and socially remote" (16). Passmore (1983) emphasizes that imagination is an essential part of what he terms the critical spirit. "Imaginatively to think through alternatives is at the same time to consider them critically" (474).

A common fallacy that sympathetic imagination can lead to, however, is the assumption that to imagine another's circumstances is necessarily to understand them and to, therefore, understand that person. Noddings (1984) takes issue with what she refers to as the "particularly rational, western,

\footnotetext{
${ }^{4}$ According to Statistics Canada, in 2005 there were 96,815 induced abortions on Canadian women. For every 100 live births there were 28.3 induced abortions. Among women under age 20 there were 13 induced abortions for every 1000 women. (See Induced abortions, The Daily, 21 May 2008. Accessed on 29 Nov. 2008 at www.statcan.gc.ca.)
} 
masculinist way" of looking at empathy as manifest in the OED definition: "The power of projecting one's personality into, and so fully understanding, the object of contemplation." The notion of 'feeling with' that she explicates in her ethic of care involves reception rather than projection. She avoids the temptation to analyze and plan; rather, she receives the other into the self and becomes a duality. As she puts it, "[t]he seeing and feeling are mine, but only partly and temporarily mine, as on loan to me" (30). In a similar reaction against the common understanding of empathy as putting oneself in another's place, Sharon Todd (2003) cites Anna Freud's comment that the process actually works the other way round: "empathizing involves, rather, putting another in yourself, becoming another person's habitat as it were, but without dissolving the person, without digesting the person" (57). Though, as Todd points out, imagining another's feelings is significant in how we think of ourselves in relation to others (56), we must take into serious consideration the fact that, in effect, this amounts to defining the other in terms of "the limits or expansiveness of one's imagination" (57). How then do we dwell with the other in the discussion of sensitive controversy without dissolving or digesting that person? As Todd contends, "engaging across differences through empathy may provide us with the raw material for selfreflection after the fact, but it cannot offer the ethical attentiveness to difference qua difference so necessary to projects of social justice" (63). ${ }^{5}$

In his conceptualization of empathy as a quality possessed by the kind of person we want to teach our children, Hare (1993) warns against those who "encourage us to believe that we cannot enter imaginatively into the lives of those whose cultural experiences we have not shared" because they "endanger values such as respect for persons and other cultures. For how" he asks, "can we respect that which we do not understand?" (159). He calls Noddings' distinction between caring as projection and caring as reception "a distinction without a difference" since, whether we step into the other's shoes or have them placed on us, "the central truth is that we have to understand how the other person sees the situation and feel how it feels to him or her" (107). "We cannot care for someone" Hare says, "without trying to understand their situation and their reactions" (108). I would suggest that the operative phrase here is 'trying to understand.' Noddings' distinction may well offer no significant difference if one assumes that understanding is the inevitable result of applying one's sympathetic imagination to the other's situation. If, however, one recognizes, as Hare appears to, that understanding is something one tries to achieve with no guarantee of success, the metaphor of reception rather than the usual one of projection could act as a reminder of the fallibility of one's efforts, regardless how well-intentioned. Though empathy is necessary to understanding the other, it is not, as Todd suggests, sufficient. To this I doubt Hare would object since he contends, following Weiss, that no one quality is

\footnotetext{
5 Todd (2003) describes her ethics as 'implied' as opposed to the traditional approach which she considers 'applied' in that one theorizes and applies regulations, rules and guidelines to educational issues. The latter "inevitably renders education as instrumental to its purpose" (5); whereas, implied ethics thinks about ethics through education (29). Although Todd acknowledges Noddings' ethic of care as allied to hers in that she (Noddings) privileges the situational aspects of ethics, Todd still considers it part of applied ethics in that "appropriate" forms of interaction are deduced from quite specific definitions of the concept [of care]" (5). It is not that Todd dismisses the role of concepts; but rather, that she warns "against the assumption that education can be a panacea $[\ldots]$ as though it can innocently reconstruct the world with better curricula, for this underestimates the powers and hazards of education itself as a practice" (6). What is not clear, however, is how her use of theoretical material from Anna Freud, Levinas and others escapes the charge of being 'applied' to educational situations. She says that exploring the idea of implied ethics "necessitates reading teaching-learning encounters for the way they promote conditions for ethicality as they promote conditions for being, both of which involve relationships between self and Other" (29). Also unclear is how this differs from what Noddings (1984) does in distinguishing her project of practical ethics from the feminine view from that of utilitarian practical ethics (3). Does Noddings positioning of ethical behaviour in human affective response differ significantly from Todd's emphasis on relationality? Hare (1993) questions the "alleged opposition between caring and principles," seeing it as another of the dualisms against which Dewey warned. He suggests that this either/or is "made superficially plausible just because having principles is portrayed in the worst possible light" (106).
} 
sufficient to make a person virtuous (15).

In my experience, pre-service teachers are quick to accept and attempt to incorporate caring into their teaching; however, they are confused by and resist Noddings' insistence that the ethic of care goes beyond caring feelings and good intentions. The question arises: "If I feel that I care, how can you say that I don't?" As Noddings says, “[c]aring involves two parties: the one-caring and the cared-for. It is complete when it is fulfilled in both" (68). She cites Aristotle's point that one process may be actualised in another, and compares her concept of care to a concept of teaching that is dependent upon learning having taken place (69). The idea that the teacher's good intentions and caring feelings are insufficient is a hard pill to swallow, but it is one Noddings believes we must accept and, I would suggest, its recognition can figure significantly in the development of teachers' ethical attentiveness. It is incumbent on the teacher educator, therefore, to help students distinguish between caring as a feeling and caring as a relationship, the first being necessary but not sufficient for the relational ethic in teaching. In discussing a sensitive controversy, caring about the other as an unactualised relation is not only not enough, it may even interfere with the confidence and calm a teacher needs in the face of such discussions. As Noddings points out, reciprocity on the part of the cared-for is what maintains the relation and "serves to prevent the caring from turning back on the one-caring in the form of anguish and concern for self" (74).

Returning to the example in which I found myself caring for a student whose cultural context may have made him or her sensitive to our in-class discussion of anti-Semitism in The Merchant of Venice, I now see the effects of unreciprocated caring. My caring became, in effect, a concern over my own concern, i.e., a concern for self, and as such was tied up in a series of what-ifs. What if there is a student here with Jewish parentage? What might he or she be thinking (of me)? What if he or she describes our discussion at home? What if I am seen as insensitive or even racist? Hare (1993) reminds us that the good teacher cares not only "because what happens to the other person will reflect somehow on our own performance, or on our own self-assessment, so that prudence, pride or personal gain become the determining factors" (101). The tack I took in that situation was to offer the standard explanation that Shakespeare's characterization of Shylock demonstrated the virulent anti-Semitism of his age and that, therefore, the play alerts us to the dangers of similar attitudes in our own time. ${ }^{6}$ I felt then that my justification was necessary and sufficient for my teaching to be critical. I no longer consider it sufficient. It served me at the time, insofar as I felt prepared to respond to my own what-ifs should I be called to account. What I failed to do, which is likely why this anecdote has recurred in my thinking about teaching to be critical, was receive the other instead of merely projecting what I imagined to be his or her reality, to use Noddings' language. Or, in Todd's terms, I was not ethically attentive to difference qua difference. One might ask if it is even reasonable to expect a beginning teacher to be capable of such attentiveness. Possibly not-however, by including in teacher education opportunities for preservice teachers to consider the pedagogical role of ethical attentiveness, the chances of its development are more likely to increase.

Beyond being attentive for signs that reciprocity has been achieved in one's caring acts and attitudes, how might the teacher attend to what Todd (2003) refers to as "difference qua difference" (63)? What conditions are necessary for the teacher to be prepared to attend to others' sensitivities, spoken or not? We shall now consider whether the concept of critical thinking offers the teacher guidance in teaching sensitive controversy.

\section{Teaching (in) the Spirit of Criticism}

\footnotetext{
${ }^{6}$ As I write I am chilled to recall a recent front-page headline in The Globe and Mail: "What kind of mother would send her child to second grade with a swastika on her arm—and then help her redraw it after a horrified teacher washed it off?" (White 2009, A1).
} 
In his influential article, "Teaching to be critical," Passmore (1983) takes the reader through various possibilities of what it is to teach a student to be critical. Neither imparting facts nor training habits and skills are sufficient conditions for teaching to be critical. Possessing facts about criticism is insufficient for being critical. Being drilled into the habit of uttering stock criticisms is also insufficient. In fact, as Passmore emphasizes, drilling students "in doctrines and in stock replies to stock objections to doctrine" is the very definition of indoctrination (26). One could develop complete mastery over a text on critical thinking, demonstrating perfect recall when questioned, without learning to be critical.

Passmore quotes Plato on skills being "capabilities for opposites"; the skillful thinker can detect as well as conceal fallacies in reasoning. An abuse of critical skills was precisely the criticism Socrates launched against the Sophists and their teachings. What Passmore calls the "forensic" skills of criticism (30), which, incidentally, he claims are likely to be developed through the practice of formal debating, are devoid of the critical spirit. It is critical thinking in this forensic sense of using skills to relentlessly scrutinise that is the version of critical thinking critiqued by constructivists such as Barbara ThayerBacon (2000). Such critiques are in effect only debunking a skills-only concept of critical thinking. This is not the version of teaching to be critical that Passmore or Siegel (1988 and 1996) advocate.

According to Passmore, the disinterested attempt to arrive at the truth requires what he calls the "critical spirit" and he stresses that the educator is interested in encouraging it in a sense by which it cannot be misused (28). ${ }^{7} \mathrm{He}$ implies that a coldly analytical, uncaring application of critical skills is not consistent with possessing the critical spirit. He compares the spirit of criticism to that of justice: "The skills of a judge, or the skills of a critic, can be used or misused; justice or the critical spirit can be neither used nor misused. And this is because neither being just nor being critical is a skill" (28). Todd (2003) raises a related point from Levinas, that ethical responsibility cannot be reduced to adherence to the laws of institutions even though justice is exercised through them. As Levinas puts it, "justice... must always be held in check by the initial interpersonal relation" (144). I suggest that possessing the spirit of criticism entails a similar regard for the encounter with the other. It is this that guards against its misuse.

For Passmore, possessing a critical spirit is a character trait and, as such, relies strongly upon the examples that are set for the student and upon "the atmosphere of the school." He illustrates how the teacher falls short of exercising the spirit of criticism by merely drawing attention to the defects before her. Authoritarian systems of education commonly "produce pupils who are extremely critical, but only of those who do not fully adhere to the accepted beliefs, the accepted rules, the accepted modes of action" (29). Here we have an example of the skills of criticism being misused. In common usage, to call a person 'highly critical' is not a compliment; rather, it implies that such a person only finds fault. Passmore suggests that being 'highly critical' is not acting in the spirit of criticism (27).

Possessing the spirit of criticism gives one the capacity to perceive when the very grounds upon which one stands need to be reassessed. As Passmore (1983) says:

[T]o exhibit a critical spirit one must be alert to the possibility that the established norms themselves ought to be rejected, that the rules ought to be changed, the criteria used in judging performances modified. Or perhaps even that the mode of performance ought not to take place at all. (30)

In teaching sensitive issues, the teacher possessing a critical spirit may feel that the very mode of critical performance ought to be suspended. Take, for example, a scenario during an in-class discussion

\footnotetext{
7 Siegel (1988) uses the phrase "critical spirit" interchangeably with "critical attitude," which includes the attitudes, dispositions, habits of mind, and traits of character necessary for one to actually engage in critical thinking (3940). He offers a useful distinction between the account of critical thinking and the account of the critical thinker; a distinction between acts of thinking and traits of persons. His reasons conception of critical thinking includes both accounts (41).
} 
in which student A takes up an example offered by student B. The teacher suspects that student B is drawing from her own experience, even though the example is couched in general terms, and that it was difficult for her to articulate this example in the public space of the classroom. Perhaps her willingness to disclose a personal, emotionally charged example is a testament to the atmosphere the teacher has worked to achieve with his students. Let us imagine further that the other student, student $\mathrm{A}$, is adept at critical analysis and begins picking apart the example from student B not suspecting, as the teacher has, student B's personal connection to it and not recognizing her resulting discomfort from being under scrutiny. What should the teacher do?

Assuming he does not want to draw further attention to student B thereby exacerbating her discomfort, the teacher could take up student A's analysis himself, engaging in furthering it with the hope of achieving a conclusion that might make student B more comfortable. I have found myself in such a situation numerous times, hearing a student A dissecting with obvious enjoyment the example of a student B sorely prepared for or inclined to engage in critical scrutiny, and I have taken on the argument myself, but not with satisfactory results because the point, insofar as the critical spirit is concerned, is not about winning an argument. The point is to encourage the critical spirit that, as Passmore says, cannot be abused. The spirit of criticism entails the dispositions, habits of mind and capacities that safeguard against the thoughtless application of critical skills. One option for the teacher under these circumstances may well be to tactfully and quickly shift attention away from the example in question and go on to other things. This action under these circumstances could exhibit a spirit of criticism on the part of the teacher.

As Passmore points out, unlike other qualities of character such as courtesy, justice and consideration, the critical spirit is a more difficult example to set for one's students (29). The foregoing scenario demonstrates how true this can be. It is likely that students would not recognize the example of the critical spirit the teacher has set. He may have used an evasive strategy, such as moving on to another topic, to cut short student A's forensic critique and, although the evasion may have been noticed, it is not likely to be recognized as part of the conception of critical thinking itself. ${ }^{8}$ For the teacher to draw attention to the example of the critical spirit he has set would undermine the very strategy he used in the spirit of criticism to save student B further discomfort. His recognizing the appropriateness of suspending the specific critical activity of the moment in order to better serve the more pressing needs of student B suggests he is able to weigh competing goods in the broader context within which critical thinking is taking place. One strategy for bringing out the practical considerations adhering to the spirit of criticism for pre-service teachers would be to offer for consideration and discussion the above scenario, or one similar to it, that suggests the importance of knowing when it is more fully critical to suspend a given critical act.

Are there traits or qualities specific to the larger purpose of judging the context and consequences of our critical thinking that ought to be considered relevant, particularly in discussing sensitive controversies? What might these be and how might they be nurtured in the process of teaching to be critical? Lundquist (1999) argues that "fundamental to learning is reflection and the ability to draw conclusions from more or less successful attempts to come to an understanding of the issues at hand" (524). In the spirit of criticism, one needs to be able to reflect upon a sensitive controversy under discussion within its emotional and socio-political context, accept that trying to understand the reality of another is contingent upon multiple factors, and hold one's conclusions tentatively. Benhabib (2006) says that " $[\mathrm{t}]$ he narrative view of culture permits one to identify cultures without falling into a correspondence theory of truth" (384), and adds that the observer of a culture "seeks for more unity and coherence in identifying a culture than does the participant." In identifying a culture, therefore, the observer and, by extension, the teacher needs to be aware of "alternative stories and competing points of view" (385) and not jump to judgment, regardless how apparently supportive

${ }^{8}$ Unless, that is, the teacher has already introduced the reasons conception of critical thinking with its critical spirit component. 
of the other she may believe her judgment to be.

If we add context to the fictional scenario above, moving it into a predominantly white, Digby high-school class who are discussing the appropriateness of requiring students to read vivid depictions of racism, and imagine student B to be the only student of colour while student A belongs to the dominant culture, how might a teacher prepare for the tension likely to arise? Instead of evading it by moving on to other things or being drawn into student A's argument, a teacher prepared for the sensitivity of this controversy might offer alternative narratives knowing, as she does, that the issue cannot be discussed without evoking thoughts of the current racial tensions in the community. She could raise competing points of view from the news reports themselves: the story of long-term harassment and intimidation versus the story of media exaggeration and fault on the part of a previous commander. Depending upon her subject-area expertise, the teacher could offer additional competing viewpoints in the form of historical or literary accounts. Were this discussion taking place in the context of studying The Merchant of Venice, the story of intolerance in Shakespeare's England problematizes traditional interpretations of Shylock the Jew. ${ }^{9}$ The examination of different interpretations of his characterization within the Elizabethan and modern-day contexts could be extended to an analysis of different points of view in news reporting on race-relations in Nova Scotia. In short then, as Todd (2003) points out, "the specifically ethical possibility of education, this possibility for nonviolent relation with the Other, can only surface when knowledge is not our aim" (15-16). This seems antithetical to the common understanding of what teaching is; yet, making sense of it is a vital step to teaching in the spirit of criticism. The role of one teaching to be critical in this strong sense is not to seek for "more unity and coherence in identifying a culture than does the participant" (Benhabib 2006, 385).

Hare (1985) points out as significant the fact that among social studies educators it is common to use the term 'handling' in reference to dealing with sensitive issues in the classroom. The term, says Hare, "suggests that the teacher needs to be wary, cautious and discreet" (116). The term 'handling' is appropriate, in Hare's view, because "in the case of empirical disputes the teacher must take care to avoid suggesting that we are closer to the truth than we are, and in the area of value disputes he must avoid the very real danger of indoctrination" (118). The term 'handling' suggests that one is taking great care as in handling something fragile or even toxic. As with any metaphor, however, it can cut both ways. 'Handling' can also connote that the handler is seeking control or mastery. ${ }^{10}$ George Dei (1996) recalls being reminded by one of his graduate students that "when academics engage in such theoretical exercises, they would do well to remember that they are talking about people's actual lived experiences of being violated, constrained and dominated" (28). Our wariness, caution and discretion in discussing sensitive controversy in the classroom must certainly focus on avoiding bias: in selecting materials and topics, in the tone of delivery, and in the overall frames of reference in which we position the topics we plan for discussion. Of immediate importance, however, is to be wary, cautious and discreet as regards the pain of others. ${ }^{11}{ }^{12}$ This must entail more than the novice teacher's litany of self-protective what-ifs

\footnotetext{
${ }^{9}$ For a debate over whether a play concerning the Arab-Israeli conflict is art or anti-Semitic propaganda, see Murphy 2009, May 16 \& 23 and Nasrallah 2009.

${ }^{10} \mathrm{My}$ thanks to an anonymous reviewer for pointing out how the term 'handling' is also implicated in the rhetoric of mastery and control.

11 An anonymous reviewer suggests that this point is so commonsensical as to not be worth making. Part of my impetus for writing this paper is a noticeable shift in the last 15 years in the attitudes of the pre-service teachers in my philosophy of education classes toward raising controversy in their classrooms. The majority has gone from fear and unwillingness to touch the controversial to an almost foolhardy impulse to include it. As I have no empirical evidence upon which to assume that this shift extends beyond the Nova Scotian context in which I teach, I am grateful to the reviewer for helping me better contextualize my concern. I would speculate, however, that popular, mass-media culture has been and is affecting people's tolerance for aggressive debate, which suggests that a renewed emphasis on caution may be needed. As an addendum to this point, there is new reason for caution in Alberta with the adoption of Bill 44. It enshrined gay rights in provincial human rights legislation at
} 
when caught off guard in discussing a sensitive issue. Reflecting on the teacher's task involves a reflexivity necessary to the spirit of criticism. With reflexivity in mind, we will now turn to the theorizing of feminist standpoint epistemology (FSE).

\section{What has Feminist Theory to Offer the Concept of Critical Thinking?}

An obvious question is why, having considered critical thinking as conceptualized by traditional rationalists, one would turn to FSE? No claim is being made here for the adoption of any version of feminist standpoint epistemology. I find the arguments for FSE unconvincing; however, I sympathize with the reasons for which an alternative theory of knowledge has been theorized and I will suggest that critical thinking theorists can benefit from some of the constitutive claims for FSE without agreeing that traditional epistemology is masculinist, misguided, and/or in need of revision. To begin, it is useful to revisit the central confusion that has resulted in so much sparring between these traditions.

In an interview with Israel Scheffler, Harvey Siegel (2005) presses Scheffler for his views on the justification of rationality vis à vis feminist claims. He asks: "Would you say that there could be some sort of gender bias in the valorisation of rationality or reason?" (650). Scheffler responds that "the notion that rationality is less suitable for women or that they are less able to reflect rationally on anything is just insulting to them" (Ibid). He goes on to explain that there are social constraints that call into question the rationality of women and it is these social inequities that need to be challenged not the high value placed on rationality (651). Siegel recounts what he takes to be the common feminist criticism; namely, that the conception of rationality in the West values "rational disputation and cold calculation" while undervaluing the private domestic sphere traditionally consigned to women (Ibid.). Scheffler then makes the pertinent point: "to what exactly is this argument an objection? Certainly not to rationality as such but rather to the way it is presumed to have been conceived" (Ibid.). It is this presumption regarding how rationality has been conceived to which we will now turn.

Sandra Harding's account of how rationality has been conceived traditionally has been one of the most influential within the feminist literature. She (1993) uses the phrase "the view from nowhere" to describe the common belief that it is possible to achieve an absolute view of reality, a view which might then be presented as if from no particular point of view and that such a view defines objectivity. Harding claims that, unlike "the view from nowhere," feminist standpoint epistemology offers a stronger form of objectivity. Rather than reject the concept of objectivity completely, Harding chooses to redefine it. To reject the concept of objectivity by means of expository argument would be a performative contradiction, i.e., contradicting one's claims through one's actions since, presumably, Harding wants the reader to accept her claims as having some purchase on reality. Harding avoids the contradiction. She defines her version of objectivity as follows: "[s]trong objectivity requires that the subject of knowledge be placed on the same critical, causal plane as the objects of knowledge. Thus, strong objectivity requires what we can think of as 'strong reflexivity"' (69). She further claims that FSE accepts individual difference without sinking into a nihilistic form of relativism, i.e., one that assumes that since nothing can be known absolutely, knowledge is worthless or, conversely, that all knowledge is of equal value. Harding claims that it is because of its strong reflexivity that standpoint epistemology

a cost of giving parents the right to pull their children out of classes dealing with sex, religion or sexual orientation, which requires school boards to notify parents in writing anytime controversial topics will be explicitly covered in class. Accessed, June 3, 2009 at http://www.ctv.ca/servlet/ArticleNews/story/CTVNews/ 20090602/alta law 090602/20090602?hub=CTVNewsAt11.

${ }^{12}$ In considering how photographic images of others' pain are being sapped of their efficacy through overuse and vulgarity, Susan Sontag (2003) argues that our sense of reality is being eroded: "There is still a reality that exists independent of the attempts to weaken its authority. The argument [that the ethical pertinence of photographs is being sapped] is in fact a defense of reality and the imperiled standards for responding more fully to it" (109). 
offers a stronger form of objectivity.

Siegel (1996) offers what I believe to be a convincing refutation of FSE. To conceive of traditional versions of rationality as dependent upon a "view from nowhere," as Harding and other feminists do, is, according to Siegel, a misconstruction. As he says, "[w]e always judge from the perspective of our own conceptual scheme; there is no way to escape from all schemes and judge from a God's-eye point of view" (175). On this, traditional rationalists are in agreement with feminists. The divergence of views hinges upon what is drawn from this. Siegel rejects feminists' claim that universality-i.e., the view unencumbered by particular points of view-is impossible. In denying the universal, one embraces it: "one can't escape the universal by denying it" (174) since the denial is itself a universal claim. In refuting certain claims made by Postmodernists, Siegel makes a useful distinction between moral and epistemological failings, which reflects the point from Scheffler above and helps counter the claim that universality is impossible. He says: "To silence or marginalize is unjustifiably to deprive people from full participation in social life. It is unjustifiably to presume that their perspectives are inferior or without value. It is to sin against them procedurally" (133). He points out that this moral failing of exclusion does not necessarily mean that the product of the resulting dialogue will not be rationally substantive; and, conversely, inclusion does not necessarily guarantee rationality. In his words, "procedural justice is neither a necessary nor a sufficient condition for substantive rationality (or epistemic worthiness more generally)" (133). In regards to the exclusion effected by Patriarchy, Siegel says: "[t]here is no Enlightenment principle which forces Patriarchy. It is rather the manifestation of deficient practice" (136). ${ }^{13}$ Though traditional rationalists would agree with feminists that specific universal claims have been misused to marginalize and oppress, they would agree with Siegel that in order to stand up against victimization we need the conceptual tools to establish principles for rejecting it in all instances; i.e., the ability and agreed upon procedures to generalize from particular instances and extend resulting principles universally, which is not to say that this proceeds infallibly. Feminist standpoint theorists would agree with Siegel that deficient practice has been rampant, but lay the blame on a deficient theory of knowledge. It is an empirical question whether or not individual interpretations of traditional epistemology, whether from a feminist or rationalist point of view, have been illogical and/or deficient in practice. But, if one portrays traditional epistemology in the best light, it is reconcilable with feminist premises regarding the role of situated knowledge vis à vis a theory of knowledge. How then have feminists construed strong reflexivity and how is it implicated in the critical spirit needed for teaching sensitive controversy in the classroom?

Harding's concept of strong reflexivity can be read as useful in the traditional rationalist's as well as the feminist's project. It is just such a capacity that is needed in the fictional scenarios of teaching to be critical considered earlier. Strong reflexivity consists of placing the subject of knowledge on the same critical, causal plane as the objects of knowledge. A controversy is sensitive because living in and through its direct effects causes one to react emotionally to the discussion of it. If she considers the initial interpersonal relation with the other secondary or tangential, a teacher can get carried away by the seeming importance of her plans and designs, and unwittingly harm the very people she intends to help. The metaphors of stepping back and gaining distance to see things in perspective can lead to the mistaken assumption that a God's-eye view is achievable. Haraway (1988) says that feminist objectivity "allows us to become answerable for what we learn how to see" (583). For a teacher to come to the realization that a sensitive issue should be taught entails a serious responsibility, and to be continually answerable for it is a condition requiring reflexive consideration of one's critical dispositions, habits of mind and affective capacities, and their pedagogical effects on self and other.

One may ask if the feminist account of strong reflexivity differs substantively from traditional

\footnotetext{
${ }^{13}$ It is interesting to note that Siegel (1996) mentions a helpful suggestion from Barbara LeClerc; namely, that certain inconsistencies in Harding's position suggest she may in fact be opposing a false universality rather than universality wholesale (fn. 4, p. 213). He also compares Harding's attempt to reconcile objectivity and situatedness with his attempt to reconcile universality and particularity (fn. 23, p. 215).
} 
rationalism's requirement for impartiality and open-mindedness in minimizing bias. By my reading, it does not differ. Hare (1993) points out that "close proximity is no guarantee of awareness and can militate against it" (3), an observation that seems to fly in the face of the feminist argument that objectivity is positioned rationality (Haraway 1988, 590). Pohlhaus (2002) is helpful here. She suggests that standpoint theory is not social enough (292), and that we abandon metaphors of place and perspective and place the emphasis on our abilities to forge relations with one another. By conceptualizing knowing as an activity within communities, struggle is struggle-with not struggle-against (290-291). I would suggest that the traditional rationalist's requirement that the critical thinker strive for the ideals of impartiality and open-mindedness can be viewed as the feminist "achievement of reflexivity to form the following question: What is the relationship between my actual social position and the ability to forge a critical standpoint?" (Pohlhaus 2002, 288).

Hare (1985) contends that it is not part of the role of a teacher as teacher to make a contribution to knowledge. This may occur, but it is secondary to the teacher's responsibility of "bringing others to knowledge, and bringing others to the point where they can make a contribution to knowledge" (116). I see no substantive difference in Hare's point and Todd's (2003) that the possibility for non-violent relation with the other must take precedence over aiming for knowledge in our teaching. Their views can be reconciled if, assuming I am correct, Hare takes 'knowledge' to include knowing how and Todd does not. Surely non-violent relation with the other requires degrees and subtleties of procedural knowledge. A student teacher or an experienced teacher may falsely assume that her contribution to knowledge should take precedence over students' needs. To practice in such a way is to fail to understand what strong reflexivity entails in teaching to be critical. Discussing sensitive controversy in the classroom brings the teacher face-to-face with difference qua difference, indissoluble in ready-mixed plans and procedures. "The critical thinker," says Siegel (1988), "must care about reason and its use and point"(40). The "reasons conception" of critical thinking rejects a distinction between cognition and affect, accepting Peters' belief that reasoning is passionate business (41). Reasoning and teaching reflexively (in) the spirit of criticism is a demonstration of character as well as an act of thinking.

\section{Conclusion}

Todd (2003) describes her project as building on tensions: two views are held in tension without collapsing the significant differences of either. ${ }^{14}$ Her strategy is one the teacher could adopt in working within and through encounters with difference in the classroom. Todd calls her approach that of taking a "doubled view," which entails letting go any need to incorporate both views. She says of the doubled view that it "paints a more complex picture of what occurs in classrooms in the here and now, one that might inform an ethical time of nonviolence, a time that is infinitely momentary" (13). I have tried to trace a path here that connects the complex nature of teaching across difference to the equally complex project of reconciling difference across theoretical traditions. In our difficult moments as teachers, attempting to discuss issues that have already stripped some students bare, it may help to remember their doubled view as they struggle to join in and block out the pain such remembrance evokes. Using Haraway's (1988) words, "I am arguing for the view from the body, always a complex, contradictory, structuring, and structured body" (589). Strong reflexivity entails this view from the body and, as I have argued and attempted to demonstrate through example, it can and does help us teach in the spirit of criticism, an attitude crucial to discussion of sensitive controversy. I have offered my own missteps and indecisions in classrooms as part of the examples here considered. Fear of recognizing and admitting my own complicity in silencing those I was trying to teach impeded my adoption of what Boler (1999) calls "the pedagogy of discomfort," which is a call to action, not by enforcing a political agenda (179),

14 The two views she refers to are the discourses of psychoanalysis and Levinasian ethics, which she takes to be incommensurable. 
but as a way of inhabiting ambiguous selves (196). "The best antiracist and antisexist work" she says, "is not about confrontation but rather a mutual exploration." In teaching sensitive controversy this would mean "to 'share' the suffering and vulnerability, to explicitly discuss the pedagogies and one's own emotional challenges" (199). As Hare (1993) reminds us, "there is no denying that some ethical issues resist universal agreement, indeed provoke violent and profound animosity. It is not wise or accurate, however, to judge the whole field of morality by the most controversial elements in it" (3). For readers dissatisfied with this inquiry, drawing from insights across traditions and discovering no clearly defined procedures for practice, I can only say that, though I share the feeling, I am learning to dwell in the ethical challenge discomfort affords.

\section{Acknowledgements}

A version of this paper was presented at the conference on Open-mindedness and the Virtues in Education in honour of William Hare at Mount Saint Vincent University, Halifax, October 4, 2008. Considerable further development to that draft is due in large part to the extensive and extremely helpful suggestions from anonymous reviewers who suggested useful readings in social justice education and critical social theory and prompted me to extend my examples to reflect insights gained from that work.

\section{References}

Boler, Megan (1999). Feeling Power: Emotions and Education. New York: Routledge.

Dearden, Robert F. (1984). Theory and Practice in Education. London: Routledge and Kegan Paul.

Dei, George J. Sefa (1996). Anti-Racism Education: Theory and Practice. Halifax: Fernwood Publishing.

Haraway, Donna (1988). Situated Knowledges: The Science Question in Feminism and the Privilege of Partial Perspective. Feminist Studies 14: 3.

Harding, Sandra (1993). Rethinking Standpoint Epistemology: What Is 'Strong Objectivity'? Feminist Epistemologies, Linda Alcoff and Elizabeth Potter, eds., New York: Routledge, 49-82.

Hare, William (1985). Controversies in Teaching. London: The Althouse Press.

Hare, William (1993). What Makes a Good Teacher: Reflections on Some Characteristics Central to the Educational Enterprise. London, Ont.: Althouse.

Hare, William \& Portelli, John. P. (2003). What To Do? Case Studies for Educators. Halifax: Edphil.

Hemmings, Heather (2000). Encouraging Critical Thinking: 'But . . What Does That Mean?' McGill Journal of Education 35: 2.

Lundquist, Robert (1999). Critical thinking and the art of making good mistakes. Teaching in Higher Learning. 4: 4.

McLaughlin, Terence (2003). Teaching Controversial Issues in Citizenship Education. Education for Democratic Citizenship. Andrew Lockyer, Bernard Crick \& John Annette (eds.). Hants, England: Ashgate Publishing.

Medel, Brian (2008a). Expert: Black history lesson for Digby Mounties would help ease tensions. The Chronicle Herald. Halifax, 26 Sept., p. B1 \& 7.

Medel, Brian (2008b). Mounties tailed me, racism expert says. The Chronicle Herald. Halifax, 27 Sept., p. A1 \& 2.

Murphy, Rex (2009). When art becomes agitprop. The Globe and Mail. Toronto, 16 May.

Nasrallah, Dimitri (2009). Rex Murphy's column last week about Caryl Churchill's play was skewed by anger and oversimplification of the play and its intentions. The Globe and Mail. Toronto, 23 May.

Noddings, Nel (1984). Caring: A feminine approach to ethics and moral education. Berkeley: University of California. 
Passmore, John (1972). On teaching to be critical. Education and Reason. R.F. Dearden, P.H. Hirst and R.S. Peters, eds. London: Routledge.

Passmore, John (1983). Education and Adaptation for the Future. How Humans Adapt. D. J. Ortner (ed.). Washington: Smithsonian Institution Press.

Passmore, John (1985). Educating for the 21st Century. The Fourth Wallace Wurth Memorial Lecture. University of New South Wales, 22 April.

Siegel, Harvey (1988). Educating Reason. New York: Routledge.

Siegel, Harvey (1996). Rationality Redeemed? Further Dialogues on an Educational Ideal. New York: Routledge.

Siegel, Harvey (2005). Israel Scheffler interviewed by Harvey Siegel. Journal of the Philosophy of Education, 37: 4, 647-659.

Sontag, Susan (2003). Regarding the Pain of Others. New York: Farrar, Straus and Giroux.

Thayer-Bacon, Barbara (2000). Constructive Thinking versus Critical Thinking. Paideusis. Journal of the Canadian Philosophy of Education Society 13:1.

Todd, Sharon (2003). Learning from the Other: Levinas, Psychoanalysis, and Ethical Possibilities in Education. Albany, NY: SUNY.

White, Patrick (2009). What kind of mother would send her child to second grade with a swastika on her arm - and help her redraw it after a horrified teacher washed it off? The Globe and Mail. Ottawa/Quebec Edition, 26 May.

\section{About the Author}

Michelle Forrest is a performing artist and philosopher of education who teaches and writes about values education and the arts. In addition to her work in philosophy of education, she is a founding member of The $(1+1+1)$ Collective, a trio of scholar-artists who demonstrate collaborative research in education through art. Contact: michelle.forrest@msvu.ca. 